\title{
EFFECT OF DIFFERENT TYPES OF WATER ON CUSP DEFLECTION OF TEETH RESTORED WITH COMPOSITE
}

\author{
Hossam Mohamed Mossa*
}

\begin{abstract}
Objective: It is in vitro study to evaluate the influence of various mouth washes on cusp deflection of premolar teeth restored with different types of composite.

Methods: A total of 45 human premolars were used in this study. The teeth were randomly divided into three equal groups according to the type of resin composite (Silorane, Bulk fill and Filtek $^{\mathrm{TM}} \mathrm{Z} 250$ ). Each group were immersed for three months in three different solutions (alcoholcontaining mouth rinse, alcohol-free mouth rinse, and artificial Saliva). The cuspal deflection was measured after curing of the composite resin and after immersion in the solution using digital caliper.
\end{abstract}

Results: All the composite resin specimens show cusp deflection. The lowest value of cusp deflection was recorded for the Silorane specimen in comparison to other types of composites. The specimens who immersed in alcohol containing mouth wash recorded the highest values.

Conclusion: Alcohol-free mouth rinse may prefer to alcohol containing mouth rinse in patients with extensive restorations

\section{INTRODUCTION}

During the last decades. The development of resin composite materials for direct restorations with improved physical and mechanical acceptable surface smoothness. Leads to increase demand for esthetic dentistry [1] Polymerization shrinkage remains a concern and a major drawback for direct composite resins as it is accompanied by stress buildup which can lead to adverse effects on the bonding to the tooth structure with subsequent marginal staining, microleakage, and recurrent caries ${ }^{[2-4]}$. When the adhesive strength exceeds the contraction stress, the restoration maintains an internal tension that pulls the cavity walls together, reducing the intercuspal distance (i.e. cuspal deflection).$^{[5]}$ the use of an antiseptic agent such as a mouth rinse as an adjunct to tooth brushing with

* Assistant Professor of Operative Dentistry, Departments of Restorative Dental Sciences, Medical Military Academy, Cairo, Egypt. 
a dentifrice may be justified, especially in cariesactive patients ${ }^{[6,7]}$. If the composite resin restorative materials bathed in saliva the water absorption will occur.The factors which affect the amount of water absorption of the composite restoration materials are filler content, curing time, the resin content, distance from composite cured and the coupling agent ${ }^{[8-10]}$. When the filler content of the composite is more the water absorption will be less ${ }^{[8,11]}$. The proper the bonding of the coupling agent the lesser the water absorption ${ }^{[12,13]}$. For resin-based composite materials water absorption may induce weakening of the matrix followed by breakdown of resin filler interface. It is also expected the hygroscopic expansion of composite that result from absorption of water may be able to compensate for the effect of polymerization shrinkage and relieve stresses ${ }^{[14]}$.

The organic matrix of conventional resin composites is generally based on methacrylate chemistry, especially cross linking dimethacrylate. The solubility of dimethacrylate based resin composites in various solutions including water and mouth rinses has been widely studied ${ }^{[15,16-18]}$.

\section{AIM OF THE WORK}

This in vitro study was conducted to determine the influence of various fluids on cusp deflection of three types of composite.

\section{MATERIAL AND METHODS}

Forty five (45) human premolars extracted for orthodontic reasons stored in normal saline were used. The selected teeth were placed $3 \mathrm{~mm}$ below the cementoenamel junction in an acrylic mold with dimensions of $15 \mathrm{~mm}$ internal diameter, $25 \mathrm{~mm}$ external diameter, and $20 \mathrm{~mm}$ height. The teeth set in the acrylic mold were fixed with a vice and a large Mesiooccluso distal cavity (MOD) cavity was prepared. The mesio-distal proximal box was extended $0.5 \mathrm{~mm}$ bucco-lingually, and the width of the axial and gingival walls of the box was $1 \mathrm{~mm}$.
The width and depth of the pulpal wall of the MOD cavities was $2 \times 3 \mathrm{~mm}$. The reference point for cavity depth was the central groove. The reference point for measuring the specimens before and after the procedure was two metal tips (cut from dental needle C-K Ject, Korea, Queens Singapore) for each specimen $(0.5 \times 4 \mathrm{~mm})$ that was fixed (using Clearfill SE Bond) horizontally and perpendicular to the long axis of the specimen at the cusp tip of the tooth, one buccally and the other lingually. The end of this tip was located beyond the buccal and lingual tooth contour by $2 \mathrm{~mm}$ in order to be attached to the microscope probes during cusp deflection measurement.

The teeth were randomly divided into three main groups (15 each), according to type of composite used. The first main group was restored with a hydrophobic resin composite (Silorane), the second main group was restored with hydrophilic one (Bulk fill) and the third main group was restored with (Filtek ${ }^{\mathrm{TM}} \mathrm{Z} 250$ ). The restoration of composite followed the manufactures' instruction. Cuspal deflections were measured using a digital micrometer at 5 minutes after completing the restoration. A Standardized LED light curing unit (Kerr - Demi -LED Light-Curing System, CA, USA) was used for polymerization of all composites (20 seconds for irradiation was used throughout the study. Each main group divided into three groups $(n=5)$ according to the type of treatment solution: distilled water, alcohol-containing and alcohol freecontaining. Each group was stored three months. Cuspal deflections were measured at the end of the storage period the measurements were made by the same operator. Cuspal deflection measurements were calculated inMicrons by subtracting the second readings from the initial ones.

The results were statistically analyzed using ANOVA followed by Student-Newman-Keuls post hoc tests $(\mathrm{p}=0.05)$. 
TABLE (1) Materials used in the study.

\begin{tabular}{|c|c|c|c|}
\hline $\begin{array}{l}\text { Tetric EvoCeram } \\
\text { Bulk Fill } \\
\text { Light cured methacrylate-based } \\
\text { bulk-fill composite resin }\end{array}$ & $\begin{array}{l}\text { Monomer matrix of dimethacrylates } \\
\text { - Fillers (Bariumglass-ytterbium } \\
\text { trifluoride-mixed oxide prepolymer) }\end{array}$ & S09720 & Ivoclar Vivadent,USA \\
\hline $\begin{array}{l}\text { Filtek }^{\mathrm{TM}} \mathrm{Z} 250 \text { universal } \\
\text { restorative composite }\end{array}$ & Microhybrid & N833614 & $\begin{array}{l}\text { 3M/ESPE, St. Paul, MN, } \\
\text { USA }\end{array}$ \\
\hline $\begin{array}{l}\text { Filtek Silorane } \\
\text { (posterior restorative) }\end{array}$ & $\begin{array}{l}\text { Silorane (3,4-epoxycyclohexylethylcyclo- } \\
\text { polymethylsiloxane, } \\
\text { bis-3,4-epoxycyclohexylethyl- } \\
\text { phenylmethylsilane) } \\
\text { Fillers: Quarz (silane layer) radiopaque yttrium } \\
\text { fluoride } \\
\text { Filler loading } 76 \%(\text { wt \%) }\end{array}$ & N236344 & $\begin{array}{l}\text { 3M/ESPE, St. Paul, MN, } \\
\text { USA }\end{array}$ \\
\hline Scotchbond etchant & $35 \%$ phosphoric acid gel & N274688 & \\
\hline Adper Single Bond Plus & Two step etch-and-rinse adhesive system & N446453 & \\
\hline $\begin{array}{l}\text { Oral-B, Pro-Expert mouth rinse } \\
\text { (alcohol-free mouth rinse) }\end{array}$ & $\begin{array}{l}\text { Aqua, Glycerin, polysorbate } 20, \text { Aroma, } \\
\text { methylparaben, } \\
\text { cetylpyridinium chloride, sodium fluoride, } \\
\text { sodium saccharin, } \\
\text { sodium benzoate, propylparaben, } \mathrm{Cl} 42051 \text {, and } \\
\mathrm{Cl} 47005\end{array}$ & 99602155 & $\begin{array}{l}\text { Procter \& Gamble MN } \\
\text { GmbH, Stra } \beta \text { e e } 1,64521 \\
\text { Gross Gerau, Germany }\end{array}$ \\
\hline $\begin{array}{l}\text { Oral-B, Advantage mouth rinse } \\
\text { (alcohol-containing mouth rinse) }\end{array}$ & $\begin{array}{l}\text { Aqua, glycerin, alcohol, aroma, methylparaben, } \\
\text { poloxamer } \\
407 \text {, cetylpyridinium chloride, sodium fluoride, } \\
\text { sodium } \\
\text { saccharin, Propylparaben, } \mathrm{Cl} 42051 \text {, and } \mathrm{Cl} \\
47005\end{array}$ & 95587215 & $\begin{array}{l}\text { Procter \& Gamble UK, } \\
\text { Weybrige, KT13 0XP }\end{array}$ \\
\hline Artificial saliva & $\begin{array}{l}\mathrm{NaCl}(400 \mathrm{mg} / \mathrm{L}), \mathrm{KCL}(400 \mathrm{mg} / \mathrm{L}) \\
\mathrm{CaCl} 2 \cdot 2 \mathrm{H} 2 \mathrm{O}(795 \mathrm{mg} / \mathrm{L}) \\
\mathrm{NaH} 2 \mathrm{PO} 4 \bullet \mathrm{H} 2 \mathrm{O}(690 \mathrm{mg} / \mathrm{L}) \mathrm{KSCN}(300 \mathrm{mg} / \mathrm{L}) \\
\mathrm{Na} 2 \mathrm{~S} \bullet 9 \mathrm{H} 2 \mathrm{O} \\
(5 \mathrm{mg} / \mathrm{L}), \text { and urea }(1000 \mathrm{mg} / \mathrm{L})\end{array}$ & & \\
\hline
\end{tabular}

\section{RESULTS}

TABLE (2) Showing the means (SEs) of cuspal deflections of tested groups in microns. Of various composite resin under various mouth washes

\begin{tabular}{|l|l|l|l|}
\hline Composite resin & Saliva & Alcohol-free containing mouth rinse & Alcohol-containing mouth rinse \\
\hline Silorane & 6 & 6.5 & 7.5 \\
\hline Bulk fill & 8 & 9 & 10 \\
\hline Filtek $^{\mathrm{TM}}$ & 10.5 & 11 & 11.5 \\
\hline
\end{tabular}




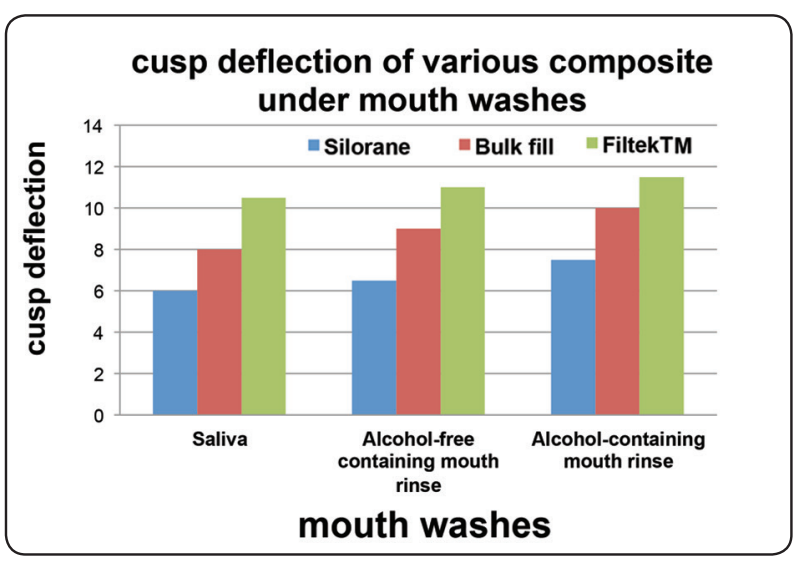

Fig. (1) Bar chart showing the means (SEs) of cuspal deflections of tested groups in microns of various composite resins under various mouth washes

All the composite resin specimens show cusp deflection. The Silorane specimen recorded the lowest value while the highest values were recorded for the filtek Z250 specimens. The alcoholcontaining mouth wash specimen recorded the highest value while the lowest values were recorded for saliva followed by the alcohol free- containing mouth wash. There is no significant difference between the bulk file specimens and the Silorane specimen while there were there is significant difference between the Silorane specimen and the filtek Z250 specimens.

\section{DISCUSSION}

Dental composites constitute an important group of materials in modern restorative dentistry [19] However, polymerization shrinkage and shrinkagerelated stress are two major drawbacks of resin composites that still need to be addressed. Resin composite materials come into extensive contact with food components, oral fluids, and drinks in the oral environment ${ }^{[20]}$. Water diffused into the resin matrix may contribute to the relaxation of polymerization shrinkage stress to some extent ${ }^{[21]}$ the expanding the polymer matrix followed by increasing the bulk volume of the resin composite will reduce marginal gaps, which generated by polymerization shrinkage, this action occurs by water sorption $^{[22]}$.
The polymerization shrinkage of the composite resins in all tested groups resulted in an inward deflection of the cusps, in agreement with other studies. ${ }^{[23-26]}$

The methacrylate group recorded the highest value this may be due to the solubility of resin composites which is related to the dissolution and leaching of various components, particularly unreacted monomers ${ }^{[27]}$. The organic matrix of conventional resin composites is generally based on methacrylate chemistry, especially cross-linking methacrylate, as in FZ250. The density of the links in methacrylate-based resin composites may vary as a result of the polymerization of free radicals, causing spatial heterogeneity that may facilitate the entrapment of residual monomers in microgels, from where they may be easily leached ${ }^{[28]}$. While the solubility of the silorane was lower than FZ250 This finding is consistent with a previous study showing silorane-based resin composites to be more hydrophobic than methacrylate-based resin composites ${ }^{[29,30]}$.

The low-shrinkage silorane-based composite resin (Filtek LS) showed the lowest significant cuspal deflection. This may be attributed to the cationic ring opening polymerization reaction of Filtek LS which results in a lower polymerization contraction, During the ring opening step in the polymerization of silorane based composite, when the acidic cations attack the oxirane rings, the cleavage and opening of these rings gain space and counteract the loss of volume occurring when the covalent bonds are formed. ${ }^{[31,32]}$ These findings may also be attributed to that siloranes have slow polymerization rate allowing time for the material to flow and for stress relaxation, resulting in a lower final degree of cuspal strain. ${ }^{[33]}$ the photoactivated cationic polymerization process of silorane resins is relatively insensitive to oxygen. Not only does this reduce polymerization shrinkage, it also increases the degree of conversion ${ }^{[34,35,36]}$. 
Bulk-fill nonflowable composite, showed the least polymerization shrinkage stress. Several factors might have affected the results. First, this material contained a shrinkage stress reliever, which is a special filler functionalized with silane. ${ }^{[37]}$ The manufacturer stated that the shrinkage stress reliever features a lower modulus of elasticity so that it acts like a microscopic spring, attenuating the forces generated during shrinkage. ${ }^{[33]}$ Second, the material included prepolymerized fillers. Resin composites typically show a relatively low elastic modulus with the use of prepolymerized filler particles. ${ }^{[38]}$ The mouth rinse containing alcohol recorded high result than the alcohol-free mouth rinse due to Ethanol, which is found in many mouth rinses, may accelerate the hydrolytic degradation of resin-based materials ${ }^{[39]}$. The mouth rinse containing alcohol produced the subsurface and surface degradation of resin composites by storing them in ethanol. ${ }^{[40]}$ These findings suggest that it may be preferable for patients with extensive restorations to avoid the use of mouth rinse containing alcohol as part of their daily oral hygiene routine so as to prevent the need for recurrent restorative treatment.

\section{CONCLUSION}

Within the limitations of this in vitro study, the following

Conclusions can be drawn:

(1) The solubility of FS was lower than that of FZ250 in all the solutions tested;

(2) Solubility of both of the restorative materials tested was lower in alcohol-free mouth rinse than in alcohol mouth rinse containing;

(3) Alcohol-free mouth rinse may prefer to alcohol containing mouth rinse in patients with extensive restorations

\section{REFERENCES}

1. Silikas N. Kavvadia K. Eliades G. Surface characterization of modern resin composites: a multi technique approach.J Am Dent 2005; 18:95-100.

2. Carvalho R, Pereira J, Yoshiyama M, Pashley D. A review of polymerization contraction: the influence of stress development versus stress relief. Oper Dent 1996; 21: 17-24.

3. Davidson CL, Feilzer AJ. Polymerization shrinkage and polymerization shrinkage stress in polymer-based restoratives. J Dent 1997; 25:435-40.

4. Loguercio AD, Reis A, Schroeder M, et al. Polymerization shrinkage: effects of boundary conditions and filling technique of resin composite restorations. J Dent 2004; 32: 459-70.

5. Karaman E, Ozgunaltay G. Cuspal deflection in premolar teeth restored using current composite resins with and without resin-modified glass ionomer liner. Oper Dent 2013; 38:282-9.

6. M. Addy, "Chlorhexidine compared with other locally delivered antimicrobials. A short review," Journal of Clinical Periodontology, vol. 13, no. 10, pp. 957-964, 1986.

7. M. Addy and J. M. Moran, "Clinical indications for the use of chemical adjuncts to plaque control: chlorhexidine formulations," Periodontology 2000, vol. 15, no. 1, pp. 52-54, 1997.

8. T.M. Chen and G. M. Brauer, "Solvent effects on bonding organo-silane to silica surfaces," Journal of Dental Research, vol. 61, no. 12, pp. 1439-1443, 1982.

9. P.L. Fan, A. Edahl, R. L. Leung, and J.W. Stanford, "Alternative interpretations of water sorption values of composite resins," Journal of Dental Research, vol. 64, no. 1, pp. 78-80, 1985.

10. C. Santos, R.L. Clarke, M. Braden, F. Guitian, and K.W.M. Davy, "Water absorption characteristics of dental composites incorporating Hydroxyapatite filler〉," Biomaterials, vol. 23, no. 8, pp. 1897-1904, 2002.

11. K. J. M. S“*oderholm, R. Mukherjee, and J. Longmate, "Filler leachability of composites stored in distilled water or artificial saliva," Journal of Dental Research, vol. 75, no. 9, pp. 1692-1699, 1996.

12. K.J.M. Soderholm, "Leaking of fillers in dental composites," Journal of Dental Research, vol. 62, no. 2, pp. 126-130, 1983.

13. J.G.Calais and K.J.M. Soderholm, "Influence of filler type and water exposure on flexural strength of experimental composite resins," Journal of Dental Research, vol. 67, no. 5, pp. 836-840, 1988. 
14. F. Keyf and F. Yalc, in, "The weight change of various lightcured Restorative materials stored in water," Journal of Contemporary Dental Practice, vol. 6, no. 2, pp. 72-79, 2005.

15. Y. Zhang and J.Xu, "Effect of immersion in variousmedia on the sorption, solubility, elution of unreacted monomers, and flexural properties of two model dental composite compositions," Journal of Materials Science: Materials in Medicine, vol. 19, no. 6, pp. 2477-2483, 2008.

16. K.Asaoka and S.Hirano, "Diffusion coefficient of water through dental composite resin," Biomaterials, vol. 24,no. 6, pp.975-979, 2003.

17. L. Musanje and B. W. Darvell, "Aspects of water sorption from the air, water and artificial saliva in resin composite restorative materials," Dental Materials, vol. 19, no. 5, pp. 414-422, 2003.

18. H. Koizumi, H. Satsukawa, N. Tanoue, T. Ogino, M. Nishiyama, and H. Matsumura, "Effect of metal halide light source on hardness, water sorption and solubility of indirect composite material," Journal of Oral Science, vol. 47, no. 4, pp. 165-169, 2005.

19. W. Geurtsen and U. Schoeler, "A 4-year retrospective clinical study of class I and class II composite restorations," Journal of Dentistry, vol. 25, no. 3-4, pp. 229-232, 1997.

20. R. Bagheri, M. F. Burrow, and M. Tyas, "Influence of foods imulatingsolutions and surface finish on susceptibility to staining of aesthetic restorative materials," Journal of Dentistry, vol. 33, no. 5, pp. 389-398, 2005.

21. A.J. Feilzer, A.J. de Gee, and C. L. Davidson, "Relaxation of polymerization contraction shear stress by hygroscopic expansion," Journal of Dental Research, vol. 69, no. 1, pp. 36-39, 1990.

22. T. Hirasawa, S. Hirano, S. Hirabayashi, I. Harashima, and M. Aizawa, "Initial dimensional change of composites in dry and wet conditions," Journal of Dental Research, vol. 62, no. 1, pp. 28-31, 1983.

23. Karaman E, Ozgunaltay G. Cuspal deflection in premolar teeth restored using current composite resins with and without resin-modified glass ionomer liner. Oper Dent 2013; 38:282-9.

24. Alomari QD, Reinhardt JW, Boyer DB. Effect of liners on cusp deflection and gap formation in composite restorations. Oper Dent 2001; 26:406-11.

25. Bouillaguet S, Gamba J, Forchelet J, et al. Dynamics of composite polymerization mediates the development of cuspal strain. Dent Mater 2006; 22:896-902.

26. Abbas G, Fleming GJP, Harrington E, et al. Cuspal movement and microleakage in premolar teeth restored with a packable composite cured in bulk or in increments. J Dent 2003; 31:437-44.
27. P.L. Fan, A. Edahl, R. L. Leung, and J.W. Stanford, "Alternative interpretations of water sorption values of composite resins," Journal of Dental Research, vol. 64, no. 1, pp. 78-80, 1985.

28. J. Malacarne, R. M. Carvalho, M. F. de Goes et al., "Water Sorption /solubility of dental adhesive resins," Dental Materials, vol. 22, no. 10, pp. 973-980, 2006.

29. W. M. Palin, G. J. P. Fleming, F. J. T. Burke, P. M. Marquis, and R. C. Randall, "The influence of short and mediumterm water immersion on the hydrolytic stability of novel low-shrink dental composites," Dental Materials, vol. 21, no. 9, pp. 852-863, 2005.

30. Y. J. Wei, N. Silikas, Z. T. Zhang, and D. C. Watts, "Diffusion and concurrent solubility of self-adhering and newresin-matrix composites during water sorption/ desorption cycles," Dental Materials, vol. 27, no. 2, pp. 197-205, 2011.

31. Weinmann W, Thalacker C, Guggenberger R. Siloranes in dental composites. Dent Mater 2005; 21:68-74.

32. Bouillaguet S, Gamba J, Forchelet J, et al. Dynamics of composite polymerization mediates the development of cuspal strain. Dent Mater 2006; 22:896-902.

33. Min SH, Ferracane J, Lee IB. Effect of shrinkage strain, modulus, and instrument compliance on polymerization shrinkage stress of light-cured composites during the initial curing stage. Dent Mater 2010; 26:1024-33.

34. N. Ilie and R. Hickel, "Macro-, micro- and nanomechanical investigations on silorane andmethacrylatebased composites," Dental Materials, vol. 25, no. 6, pp. 810-819, 2009.

35. N. Ilie and R. Hickel, "Silorane-based dental composite: behavior and abilities," Dental Materials Journal, vol. 25, no. 3, pp. 445-454, 2006.

36. W. Lien and K. S. Vandewalle, "Physical properties of a new silorane-based restorative system," DentalMaterials, vol. 26, no. 4, pp. 337-344, 2010.

37. Scientific documentation of Tetric N-Ceram Bulk Fill. Retrieved online September 2012 from: http://www. ivoclarvivadent.co.kr

38. Blackham JT, Vandewalle KS, \& Lien W (2009) Properties of hybrid resin composite systems containing prepolymerized filler particles Operative Dentistry 34(6) 697-702.

39. S. Y.Lee, H. M. Huang, C. Y. Lin, and Y.H. Shih, "Leached components from dental composites in oral simulating fluids and the resultant composite strengths," Journal of Oral Rehabilitation, vol. 25, no. 8, pp. 575-588, 1998.

40. J. L. Ferracane, "Hygroscopic and hydrolytic effects in dental polymer networks," Dental Materials, vol. 22, no. 3, pp. 211-222, 2006. 